Impact of Globalisation on the Development of Ethnic Groups 


\title{
Impact of Globalisation on the Development of Ethnic Groups - The Case of Nigeria and China: Prospects for Sino-Africa Cooperation in Poverty Reduction
}

\author{
Guo Zhanfeng ${ }^{1}$, M. Agri Eneji ${ }^{2}$ and Francis O. Odey ${ }^{3}$ \\ ${ }^{1}$ Division of Development Economics, College Of Humanities and \\ Development, China Agricultural University, Beijing - China \\ ${ }^{2}$ Departments of Economics, University of Jos, Nigeria \\ ${ }^{3}$ China Foreign Affairs University, Beijing - China
}

\begin{abstract}
This study is consequent upon the similarities and dissimilarities between these two countries of the south-south in their development cooperation. Both countries have population which is an asset (potential market) to globalization and international trade. The two countries have enormous natural resources, endowed with abundant labor as a cheaper factor of production. They are also multi-ethnic with larger rural areas than the urban region. The People's Republic of China is the most populous country in the world, while the Federal Republic of Nigeria is the most populous country on the African continent. Both countries are developing, though China on a faster track. Nigeria was forced into colonialism fully, but China partially. China faces external influences on the Taiwan issue; Nigeria also faced external influences on the Bakasi Peninsula. Economic liberalization started in China in 1978; it has been there in Nigeria even before independence, prompting the discovery of crude oil in 1958. China drilled her first oil in 1959. In the language of political economy, China is communism (centrally planned), while Nigeria is a mixed economy. In the dawn of a new era in development, "China Africa" development cooperation based on equality and mutual respect, what does the historical impact of globalization on the development of ethnic groups holds for the future of these two countries in particular and Africa in general? What lessons can we learn from the past? And what new strategy and prospect for China Africa's sustainable development? The methodology include field visits, interview and literature review.
\end{abstract}

Keywords: Global competition, ethnic group, natural resources, Environmental degradation, Oil pollution, Deforestation, Trade imperialism, poverty reduction.

\section{INTRODUCTION}

Globalization is fast transforming the very principles of society and institutions. The continued technical, economic, political and cultural development of global capitalism has gradually revolutionized its own social 
foundations (Tade, 2004). It is fast stripping the nations and creating a new kind of society, a new kind of nature and a new kind of everyday gap between the rich and the poor, as well as a new kind of state; an endless growth of production and consumption. It is rapidly changing the relations between the local and the global, the domestic and the foreign which affects the very meaning of development and self-reliance as several patterns of collective life are being eroded. The study takes a look at such ugly dimensions from the perspectives of the Niger Delta development in Nigeria and ethnic minority development in China for poverty reduction. From transatlantic trade, colonialism, neo-colonialism, or globalization, the methods employed, theory and practice of the policies are primarily not for sustainable rural and community development. But merely to exploit the community-based natural resources (Ronnie and $\mathrm{Li}$ Xiaoyun, 2009) unsustainably for profits. In the whole century from 1890-1990, agriculture and mining activities in Asia, Africa, and Latin America came dominantly within the web of globalization (Bukwoski and Barnabas, 1999). These continents and countries constituting them remained backward (Toyo, 2001). Globalization failed in one whole century of expanding world trade to turn these countries' fortune around. The fastest rates of both growth and development ever seen in a modern world were witnessed in the Union of Soviet Socialist Republics between 1920-1939; in China between 1952-1958, and again since 1978; and Eastern Europe in the period 1952-1970. Yet, these countries were totally closed to the global economy of imperialism. They were closed partly by embargo and partly by their own choice. Imperialist big business has scientific, technological, industrial, trading, financial, transport, business construction, telecommunication and information hegemony over the world (Shepard and Hayduk, 2002). Global competition and trade imperialism often involves falsehood, a monopolistic propensity, dishonesty, duplicity, antagonism, and all kinds of trade malpractices (Toyo, 2001). It is the hegemony of one (advantaged) nation over another (disadvantaged) nation with the aim to profit. Usually, backed with the use or threat of military, political, economic power to force issues, this is what makes the minority ethnic groups to suffer beyond measure. It may be asserted by various forms of colonialism, neo-colonialism, of trade, investments, landlordism, financial manipulations including currency, foreign exchange and credit manipulations, exploitation of human and natural resources, using many forms of organization and many kinds of policy. By contrast, global imperialism all through history has resulted and continues to result in increasing the gap between a wealthy few and a poor majority, accompanied by environmental and cultural crisis in various forms. In the words of Owens Wiwa (2001), "globalization is fraught with paradoxes". While it increases the prosperity of the West and shareholders of the world's transnational corporations (TNCs), it also increases the poverty of the world's poorest people and those minority ethnic groups that live in resourcerich rural areas but are poor, hungry, homeless and sick. The remaining part of this paper discusses the cultural impact of globalization on the ethnic 
groups, the environmental and socioeconomic impact with some cases from Niger Delta and China ethnic minority, ChinAfrica cooperation for poverty reduction and the conclusion.

\section{Cultural Globalization}

Cultural education has been rapidly globalize; the minority ethnic groups are not left out in the process. Ademola (2007) defines culture education as "the peculiar means and methods of instruction by which a society imparts its body of values and mores in the pursuance and attainment of the society's collective vision, aspirations and goals". Indigenous language, oral traditions and customs, music, dance, festivals, traditional medicine, food ways etc have become so flexible in a way that threatens social cohesion (Ayandiji, 2006).The methodologies and means of dissemination, teaching and acquisition of western culture in the aspects mentioned above, in the face of globalization, is rapid and at the expense of the local. Given that culture is life, and that it defines a people's identity, something has to be done urgently before the locals completely lost their identity. Fashion is a significant expression of cultural identity. However, this important identity is eroded by modern dress styles. Young and old people have simply lost confidence in a symbolically traditional dress code. Western identity has become the dress code. Food ways have changed, McDonalds, Mr. Biggs, and other fast food and pastries are being globalised with side effects on individual's traditional food ways. Today, some families have social conflicts because none of the spouse can cook. Coca-Cola is fast displacing water as the world's drinking choice. Global imperialism has destroyed cultural values in the third world, addicting the average and upper political class to wasteful consumption, and irrational taste for foreign products at the expense of local industries and people. It has multiplied the weapons of war, and increased global insecurity and uncertainty. On sports globalization, teacher and students are having disagreements over an important class when the club side is playing football in the television. Talented players are adopted with half education to Europe and abandoned after their carrier, what next? Football-related disaster is claiming hundreds of lives of youths and men, leaving women widows, and children orphans; in South Africa (2001), Ghana (2000), Liberia(2008), Ivory Coast(2009), the ones in Congo and Togo are no exceptions. The taste for sports is almost becoming idolatry and quirky. The impact of globalization is associated with the destruction of cultural identities. The local culture is constantly infiltrated with western culture, in what is termed cultural imperialism (Shepard and Hayduk, 2002). The culturally sustainable ties among the ethnic groups is destroyed, displacing people and putting in place western culture copied from the internet, website, television, video, MPs (Lull,2000, Thomson,1995). There is the abstraction of social and cultural practices from the contexts of local or traditional particularity for the sake of modernity. The cultural practices are proliferated by life in the movies; crime, robbery, dollarization, materialism, imperialism, bodily passion, 
falsehood, deceits, double standard, so-call smartness, hastiness etc. Globalization distributes these features across all ethnic groups around the world, as rural problems; poverty, water crisis, diseases, illiteracy, infrastructural decay, social and environmental injustices increase for the minority ethnic groups.

\section{Case 1: The Case Of The Niger Delta.}

Nigeria, a West African country, is the world's eight largest oil exporter. This mineral is exploited in the Niger Delta, which is in the South-South of Nigeria. The Federal Republic of Nigeria operates a three-tiered system with 36 states divided into 774 Local Government Councils (LGCs), and Abuja as the capital. This former British colony gained independence in 1960, but started oil exploitation in 1958 by Royal Dutch, Shell. Up till date, oil contributes about $94 \%$ of her export (Akpbibibo, 2003). The Niger Delta, a minority group in Nigeria, comprise of Rivers, Cross River, Bayelsa, Delta, Akwa-ibom, Edo, Abia, Imo and Ondo states. About 20million (15.6\%) of Nigeria's population, 40 ethnic groups, 250 dialects and 300 communities constitute the Niger Delta region. This region is responsible for about $85 \%$ of total government revenue (Ojokorotu, 2008). The fact in the Niger Delta is that over the years, the Nigerian state has sought to maintain relations of power that gradually undermined the position of the minorities (Collier and Hoeffler, 2004). Nigeria, the most populous Black nation, is indisputably one of the most richly endowed countries on the continent. Her immense resources-human and material, and potentials for rapid industrialization, provide opportunities for sustainable and self-reliance national development, but has always been underemployed. Paradoxically, $70 \%$ of Niger Delta's 20million people are living below the poverty line (Humphrey et al, 2007). This is the region where Gross National Product (GNP) per capita and educational levels remain below national average. The environmental impact of oil pollution has been disastrous, due to frequent oil spills and to the common practice of gas flaring. Deforestation and quarrying activities to meet the needs of rapid and uncontrolled urbanization have been exploited to the burden of environmental degradation (Idemudia and Ite, 2006). Livelihoods have traditionally relied upon fishing and farming. These vital resources are now severely compromised by the effect of water, land and air pollution, degradation of arable soils and land seizure. Conflict and violence have been persistent since the 1990 s, due to multiple and intricate factors (Pegg, 2006). These have created a climate of rebellion and insecurity, culminating recently to the frequent hostage taking, hi-jacking, and kidnaps of foreign oil workers, a threat to the sustainability of industrial investments. Political repression and massacres of rebellious communities by official authorities are well documented, for instance, the Umuechem massacre of 1990(Karl, 2007). The Niger Delta region is most affected by HIV infection due to the combined effects of poverty, urbanization, unemployment, and migration of foreign or national laborers (Ayandiji, 2006). In most of the 
Local Governments in the region, social services; health, education, transportation, communication, electricity and facilities run by Local Government authorities have nearly collapsed, primary health care services are epileptic. Oil exploration and exploitation has plagued more rural communities than helped them. There is poverty, widespread inequality, high rates of child mortality, lower life expectancy, and higher malnutrition rates. Community value has been marginalized and instrumentalized by multiple dimensions of deprivation. Adversely, oil exploitation has affected the Ijaw, Ogoni, Isoko, Urhobo, Itsekiri and other communities. The lives and livelihoods of the ethnic groups have become unsustainable. Streams and creeks are polluted by oil sills and well-blowouts, air poisoned by nitrous oxide, sulphur dioxide, carbon monoxide, hydrocarbons and underground water polluted with crude oil (Seranno and Isagani,2005). Inhuman business and trade malpractices of transnational corporations in Africa is not limited to Nigeria and point to the urgent need for a new brand of Africa international cooperation, for instance, the ChinAfrica cooperation. The initially well organized egalitarian African society with very healthy symbiotic relationship with the natural environment which is now displaced by western globalization and trade imperialism could again be regained through this kind of South-South cooperation. Instances abound; the problem of the Umlazi community in South Africa with shell and BP, the Sudanese peasants and Talisman, the illegal gold mining in Angola (Thomson,1995) , are good examples of western imperialism on Africa. The images of these impoverished communities are played out occasionally on television by environmental and activist organizations. They represent the paradoxes of global imperialism on this promising continent. Similar scenarios have been seen played out between Trans-national Corporations (TNCs) and indigenous peoples all across the continents of Africa, Asia, South America and North America.

\section{Cases From China}

Since ancient times, China is a unified multi-ethnic country. In China, there are 55 ethnic groups and 1 Han majority which have occupied absolutely population. Because other 55 ethnic groups "population is much smaller than the Han Majority and is customarily referred to as "minority". In 1990, China's fourth census data shows that the Han population accounts for $91.96 \%$ in the country's total population, while ethnic minority population accounts for $8.04 \% \quad$ (Jiangping, 1994 ). In 2000, according to the fifth national census statistics, the Chinese has 1.29533 billion people. the population of Han Majority is 1.1594 billion, accounting for $91.59 \%$; the population of ethnic minority is 106.43 million, accounting for $8.41 \%$ (in 1990 with the Fourth compared to national census, the Han population of $116,920,000$ people, an increase of $11.22 \%$; the minority population increased by $15,230,000$ people, an increase of $16.70 \%$ ) .

Since the establishment of new China, the State puts equality and national 
unity as a solution to the ethnic issue of the basic principles and fundamental policies. The system of regional autonomy for minority Peoples is a basic policy and an important political system. "Constitution of the PRC" stipulates: "all nationalities of The People's Republic of China are equal. The State protects the legitimate rights and benefits of the minorities, safeguard and develop all ethnic groups in equality, solidarity, mutual aid relations. The prohibition of any ethnic discrimination and oppression is also emphasized".

China's regional autonomy for minority Peoples are under the unified leadership of the places inhabited by ethnic minorities exercising regional autonomy, the establishment of self-government, the exercise of autonomy, so that ethnic minority people are the masters of self-management of the autonomous areas of internal affairs. China's ethnic autonomous areas are divided into autonomous regions, autonomous prefectures and autonomous counties (banners). By the end of 1998, China has established 155 ethnic autonomous areas, one of five autonomous regions, 30 autonomous prefectures and 120 autonomous counties (banners), as well as 1256 autonomous townships. In 55 ethnic minorities, the state has set up 44 places for autonomy. Autonomy of the minority population of ethnic minorities accounted for $75 \%$ of the total population of autonomous local administrative region, the size of the total area of $64 \%$. Self-government places the number and layout, witch basically adapts with China's nationalities distribution and composition (Wangshimin, 1996,).

China made remarkable achievements to help the poor. Ethnic group also have made gratifying results in the field of poverty alleviation. However, because of historical and geographical conditions and other reasons, compared to a small number of economically developed areas, these ethnic group areas are still undeveloped. Distribution of all nationalities in China is characterized by: large mixed, small live, live intertwined. There is ethnic minority in Han majority areas, there is the Han nationality living in ethnic minority areas. This distribution pattern is a long-term historical development of the process of interaction between various ethnic groups; formed by the migration Although Chinese minority population is small, but a very wide distribution. At present, the Chinese minority are mainly distributed in Inner Mongolia, Xinjiang, Ningxia, Guangxi, Tibet, Yunnan, Guizhou, Qinghai, Sichuan, Gansu, Liaoning, Jilin, Hunan, Hubei, Hainan and Taiwan provinces, autonomous regions (Wangshimin, 1996,). Judging from the distribution of ethnic minorities, the majority people of ethnic minorities living in mountainous areas, borders, transport facilities, places of economic underdevelopment. With the development of globalization, the cultural resources of ethnic minorities are welcomed by the outsiders cooperates. Therefore, the culture industry of the ethnic minority areas first emerged, and these ethnic places go from closed to open. Cultural resources in ethnic minority areas are the most important and most precious resources. the unique culture, magical religions, beautiful environment, long and splendid history and special folk customs of ethnic minority areas are the basic components not only to attract tourists, but also to attract local governments 
and enterprises to get the great economic returns earned by the "signs", thus creating the so-called " economy Sings Opera in cultural Stage, " situation. Yunnan is also first proposed building on the "Culture" of the goal in 1996, clearly put to cultivate the cultural industry in Yunnan Province as a new economic growth point and a new pillar industries. However, the culture industries in ethnic minority areas also generally only used as part of tourism resources, development is still in the plane, a single status. Culture has not yet formed the industrial chain, that is, the tourism industry as a leader, led the development of related industries, have to be developed for in-depth. (Lirui, 2004)

Globalization brings negative impacts to cultural rights of ethnic groups. Case 2

Reviewing the past study, we think the most misunderstanding at present cultural commercialization in ethnic group is that local government and enterprise dominate its development, and ignore the cultural rights and benefits of people of ethnic group. And then we take the example for "DongBa paper" from Naxi ethnic group the LiJiang prefecture in Yunnan province (Zengyiqun, Guozhanfeng, 2009). Naxi nationality, with more than 300 thousand people, live in the northwest of Lijiang, Yunnan, Shangri-La, Weixi, Muli of Sichuan province, Yanyuan and other places. And the cultures of Dongba culture become famous home and abroad. Still now Nazi's pictograph and picture has been preserved, which pass on and master by the DongBa in history, thereby is referred to as the "Dongba writing" for daily writing. The "DongBa Book" is called as "shenjiu nuju" in Dongba language, which means "the language carved in wood or stone". And the paper for Dongba writing in the Naxi language is referred to as the "pigment", for the external calling, which is referred to as the "hand-made-paper "in Chinese. Our interviewee - He Shengwen, who is last successor of "Dongba paper", lives in the village of Ken Peigu in DaJu County in the north of Lijiang River. And the DaJu county is situated in the north of snow mountain of Yu Long, where is connected with Hu Tiao gorge in the west, and is on the opposite bank of San Ba village in Zhong Dian County. There are three administrative villages, 31 villager groups, and the size of the total area is 332.55 square meters. Besides the main Naxi group, it also includes Han, Tibetan, Yi, Lisu and other ethnic groups, and the main crops cultivated are wheat, potatoes and so on, while the main source of income relies on Baiyun beans, cattle, pigs, and sheep. "Ken Peigu" in the Naxi language means as "the place to do Reclamation", and belongs to the Villagers Committees of Bai Mei village in $\mathrm{Da}$ Ju County which is located 86 kilometers north of Lijiang County. There are 15 kilometers roads from the government of $\mathrm{Da} \mathrm{Ju}$ County, with the altitude of 2645 meters, which is a typical region of alpine mountain. In 2003, The village have 46 doors, with a total population of 189 , including 95 male, 94 female, and one Han people and one Bai people who married the local people and the rest are the Naxi. The village of Ken Peigu 
has a traditional history of making the "Dong Ba paper", which has a long standing reputation at the local industry. The paper produced is referred to as the "Dagu Shengsu", which means "the paper of Ken Peigu village." According to the survey, the history of the Ken Peigu shows that (see table 1) in 1930 's, the family of papermaking in the whole village accounts for about $47 \%$ of the total number of households, but in 2003, only one person still worked on (He Shengwen) papermaking. In $1989 \mathrm{He}$ Shengwen embarked on the restoration of paper-making technology, and makes an official establishment in 1990, with name of fixed-point paper-making workshop of Lijiang Dongba Cultural Research Institute.

Because of religious and political factors, Dongba paper was suspended for 42 years (1949-1991). In 1990, the only person named He Shengwen always was making paper home, which few persons among the young generations mastered. He Guishan in 2001 also learned the paper, but devotion of less time. In May 2003, with the support of seminar of biodiversity and traditional knowledge in YunNan province, the elder who master the paper-making techniques could train six young people in the group form. They are: $\mathrm{He}$ Guixiu (village head at present), He Chunlong, He Guoqiang, and Chunlong, He Runlin (the former village head), and He Shiying respectively. However, since the lack of market information, they are almost no papermaker. And $\mathrm{He}$ Guishan had been studied the techniques from his grandfather here before (the old Dongba). Still in 2003, only was sold at 700 Yuan, and in 2005 was sold at 300 Yuan to Zhi-guo (3 Yuan / sheet), now has 300 sheets accumulated. He Chun-lin in 2006 created only 80 sheets, stored in the home. Other people hardly make paper; the economic resources depend mainly on farming income, sub-strain (Songqi, red strain), herbal medicine and so on.

Table 1: the number of households making paper in KenPeiGu village.

\begin{tabular}{lll}
\hline Time & $\begin{array}{l}\text { Household } \\
\text { number }\end{array}$ & $\begin{array}{l}\text { The number of Household } \\
\text { Making paper }\end{array}$ \\
\hline 1927 & 11 & 4 \\
1937 & 17 & 8 \\
1947 & 20 & $\begin{array}{l}\text { 2 professional making paper } \\
\text { household, and 2 household for part- } \\
\text { time }\end{array}$ \\
& & 0 \\
1949 & 22 & 0 \\
1959 & 32 & 1 \\
1991 & 41 & 1 professional making paper \\
2003 & 46 & household, and 1 household for part- \\
& & time \\
2006 & 48 & 3 household for part-time \\
\hline
\end{tabular}

Since 1980's, with the rejuvenation and in-depth study of the Dongba culture, a number of scholars and civil elites began to observe the significance of cultural heritage for the NaXi historical development as well as the Dongba paper. So with their support, the Dongba paper manufacturing technology 
was restored. While with the development of tourism, the technics of Dongba paper approached commercial establishments from the villages, to create economic benefits with the DongBa words and paintings.

However, according to the research, in Lijiang, some companies have began to make an application for patent in the name of a production process of DongBa paper in the present maker and sell their products. but the sold products is not unique to the local manufacture of Dongba paper which is made from the flower of Yao, but paper-making materials to buy more cheaper from other provinces (Guizhou, etc.), so the local products( Dong Ba paper) are repelled from the market completely, and obtain substantial profits in the name of Dong $\mathrm{Ba}$ paper. From the above Case, we can see the Naxi people's cultural rights had been violated, that is, the collective cultural rights of KenPeiGu village are infracted by non-performing commercial acts during the economic development and this violation makes the cultural heritage protection face greater risk.

Similarly, Wang Sidai from Yunnan Nationalities, a University Professor has researched about tourism Garden of Xishuangbanna in Yunnan Province. He found that cultural benefits of the distribution in the "company + farmer" mode, in 2005 the economic interests ratio of outside enterprises and local villagers are $85 \%$ and $15 \%$, disparity is too large. In his view, the overall distribution of benefits is unfair to owners of cultural resources, and economic resources into the distribution of benefits to create a strong inverse; Governments, corporations and the villagers do not have a strong sense of a fair distribution of benefits; villagers of its own culture in the process of industrialization do regards the cultural resource with low economic value, and lack of awareness of cultural protection. The agreement that the company signed with the villagers prevent fairness question of interest of the settlement (agreement in the form of law to safeguard the acts of unfair benefits); local government throughout the development process has not played well role of safeguarding the interests of fairness (Wangsidai, Luoping,2009).

\section{Case 3:Globalization bring impacts to women of ethnic group}

The Case study about costumes industrialization of $\mathrm{Yi}$ nationality in Dongchuan District of Kunming is fully described that the hard work is paid by the Yi women in national costumes, handicrafts, etc. But in the process of global economic integration, the commerce and trade which is the mostly low-end of industrial chain in the circulation of commodities often meet something very unjust and unequal.( Luo Ronghuai, Qiaozhaoqi,2009) (1) The basic overview of the economic and social development. Bai Nijing group which belongs to Tuo Luo administrative village in A Wang township lies in the south of Dong Chuang district, which is located 15 kilometers in the turnoff along the road from the Dongchuan to Kunming. 
After entering the main roads which is in and out, limited by weather condition, we can arrive at the county leaving more than ten kilometers mountain road, with an average elevation of about 2400 meters. Bai Nijing group at the present has 49 households with more than 200 people, $100 \%$ of the Yi nation, which are poorer mountain villages and one of five collective places of the Yi people in A Wang Township. Since the influence of factors such as climate, geography and lower level of other natural and social development, the peasants have engaged in production and living by semifarming and husbandry for a long time, in the condition of a weak agricultural infrastructure, difficult problem of drinking water, a lower level of economic and social development . Here Per-capita possesses of about 1.5 acres of cultivated land, and the main crops are: potato, maize, buckwheat and a small number of Rapeseed oil .And the main animals to feed are pig, chicken, beef; each person is keeping an average of 6 pigs, 1-2 head of cattle and more than 10 chickens. Goat were reared once before, but in recent years, since the implementation of closing hillsides to facilitate afforestation, farmers lose the condition of goats rearing and have to give up. The main cash income for the family rely on the outside work as a casual laborer and the sale of vegetables, pigs, chickens, which is for the purchase of salt, toothpaste, soap and other necessities of daily life. The village of Bai Nijing in 2005, there are 500 kilograms grain per capita production and 600 Yuan net income per capita. And parts of Yi group, have break away from the difficulties of food and clothing needs, but a significant portion of the villagers did not have adequate food and clothing, the task of poverty is also a long way to go. Protection, development and utilization of traditional cultural resources of the Yi nationality, are not only the protection of traditional culture of the $\mathrm{Yi}$, but also one of the ways to increase the economic income for local people. (Luoronghuai, 2009). (2) retain traditional culture of the Yi nationality more completely The village of Bai Nijing still have retained more traditional culture of Yi nationality, including culture of traditional holiday, language and culture, fashion culture, food culture, religious culture and religious beliefs. The most prominent are: the production at work and daily life, the villagers to communicate with each other in their own language and the meals, worship and religious activities in accordance with the lifestyles of the Yi. What is as same as the customs of the $\mathrm{Yi}$, the apparel production is finished in a straight line by women from first moment to the last. It is the most popular for the Yi's women to spin and weave crafts in Bai Nijing, to such an extent that every household embark on the textile weaving, to make the clothing of their own(Luoronghuai,2009).

(3)The technical procedures for apparel production Under normal circumstances, for Yi's women achieving a set of clothes, requires more than 10 manual technical process, for example it includes the acquisition of raw materials (mainly made from wool, thread, cotton and lace, etc.) - Cleaning -drying- spinning lines - weaving - dyeing - reduction - 
sewing - parquet and Other accessories . Its arts and crafts show the style of concise, rugged, simple and natural features. The available resources of raw materials is mainly purchasing in the market of nearby village. And it normally takes 3 hours to work, besides this process; parts of processes could be completed by men or women.

Qiao Zhaoqi (2009) in the survey found that farmers produce a set of Yi's dress producing is often spend for a long time by local people from the spinning wire, dye, textile, to create clothes, because the production of farmers depend on the individual work but not the workshop. in the current market conditions, sales price of a dress is 300 Yuan, and the production costs of farmers (excluding labor costs) is 150 Yuan, while rural households can only get 180-200 Yuan for sales revenue, and the profit is 30-50 Yuan, which are $20 \%-30 \%$ of the spending costs, while the distributor can gain more than 100 Yuan. If the cost of human resources is included, in accordance with the production of a dress required the average labor costs are 1-1.6 Yuan every day, which is very low. Qiao Zhaoqi (2009) also believes that the second role of farmer is the distribution of benefits between government and distributor, which is also the main point to study. The situation of farmers in this transaction being absolutely vulnerable groups, mainly has decided by the current market. First, farmers are confronted with the narrow market, because of the Sub-village located in the region 2400 meters above sea level, temperature is lower than 6 -- 7 degrees in urban region of Dong Chuang, and the road to the village limited by weather and no bus accessible, car's entering about 1 hours required. If the farmers need to walk around 2-3 hours, few distributors enter village to purchase that is decided by the certain condition of local traffic, or small number of vendors, and local farmers in general have such a capacity that it is bound to form the situation of supply exceeding demand for the number of dressing, so the distributor can depress prices for farmers to win super profits, but farmers only get the normal profits.

\section{POVER REDUCTION FOR ETHNIC GROUP IN CHINA}

After many years, poverty alleviation and development in minority areas has made great achievements. First, poor people greatly have been reduced. From 1994 to 2003, the poor population in ethnic minority areas has reduced from 45 million to $13,040,000$ people. Second, farmers' net income from 404.09 Yuan in 1992 rose to 1340.7 Yuan in 2003. Third significant improvement in infrastructure. By the end of 2003, the proportion of ways, electricity, telephone and the villages of Health Office of in the total villages, is respectively $70.4 \%, 90.40 \%, 44.6 \%$ and $61.1 \%$.From the distribution of poverty, Seven-year Priority Poverty Alleviation Program (a program designed to life 80 million people out of absolute poverty in a period of seven years from 1994 to 2000) from the state included 592 poor counties, but 257 ones are poor ethnic minority counties, accounting for $43.4 \%$. In order to ensure the timely completion of the target poverty, besides the state gives 
some preferential policies to the ethnic minority areas just like the Han majority, also gives some special and preferential policies 。

(1) Special care to improve standards, to expand the scope of supporting ethnic minority areas. In 1986, the State Council determined the criteria of poverty alleviation counties: in the general poverty areas, net income of peasants per capita below 150 Yuan throughout the county in 1985, but the old revolutionary areas and ethnic autonomous areas to get to 200 Yuan (300 Yuan in pastoral areas). in 2001, the State Council, implemented the "Outline of China's rural poverty alleviation and development (2001-2010)", and also focused on the areas where the poverty population is concentrated in central and western minority areas, old revolutionary base areas, border areas and destitute areas. (Bie Zhenyu, 2008).

(2) Poverty relief funds and materials have precedence over the poverty alleviation counties of ethnic minority areas. The size of bank loans and fertilizer, diesel, agricultural plastic sheeting and other means of production in ethnic minorities are priority to being arrangements. The country's investment in agriculture, education funds, Welfare-to-work, food and clothing projects focus on the ethnic minorities and the distribution of the proportion of are significantly higher than other areas. According to statistics, from 1995 to 1997, the state has given 14.2 billion funds to the autonomous regions of eight provinces to accelerate the pace of poverty.

(3) In 1999, The "Program to Develop Border Areas and Improve the Lives of the People There" was launched by the State Ethnic Affairs Commission. Because in 135 border counties, there are 107 ethnic autonomous areas, and in 21 million of the total population of the border, the ethnic minority population accounts for $48 \%$. By the end of 2003, the fund of "Program to Develop Border Areas and Improve the Lives of the People There" has reached 15 billion Yuan, which is to obtain good results.

These special polices shows that the Chinese government absolutely focuses on anti-poverty work of ethnic minorities, but also to takes some of the above-mentioned preferential policies, and achieves good results. Presently, the Chinese government's support for ethnic minorities is mainly as an important aspect of economic development. Therefore, the Government is too much to emphasis on economic development, so, to some extent, ignores to protecting the cultural rights of the local people in ethnic groups, which results in a number of minority farmers into a weak position during the process of economic globalization.

\section{Chinafrica Cooperation In Poverty Reduction}

China has contributed immensely to the African struggle against colonialism and racism, its material assistance for the development of the continent, and its role in defending the sovereignty of African states. In the 1960s, China supported the construction of the Tazam railways which linked several African countries. Nigeria- China diplomatic relations was established in 1971, followed by a state visit of the then Head of State, General Yakubu 


\section{Guo Zhanfeng, M. Agri Eneji and Francis O. Odey}

Gowon to China. Over the years, Nigeria and China relation has become more important with its friendship manifesting in all spheres of collaboration that have mutual benefits for even the common man and woman on the street and community; rural telephony system, the Mabilla and Zungeru hydropower projects, export credit financing, free trade zones in Lagos and Imo states ( job creation from Lagos free trade zone alone is expected to be around 300,000 within the next five years), the power plant in Ogun and Ondo states. Manufacturing; Haier, Huwei, manufacture of household and office equipments, Henan Gongyi Cangxi industry in Benue state, sugar Mill in Jigawa state, the air conditioner plant, cooperation in agriculture, other technical assistances in Research, education, health etc. The Sino- Africa cooperation, known as Forum for Africa Cooperation is also having desirable effects on China- Nigeria relations. In 2006, at the first ever China Africa summit held in Beijing, China announced her genuine policy measures for stepping up cooperation with Africa. Under these measures, a China- Africa Development Bank has been established. The basic national condition of modern China as; the largest population in the world of over 1.3 billion people; the third largest territory of 9.6 million sq. km; the highest foreign reserve at US\$1.98 trillion; the biggest coal producer in the world; a multiethnic nationality with 56 ethnic group, with 5000 years of civilization; the unique reform/opening up as the biggest developing country; all show that Africa can learn a lot from China's experience. The peculiar ideals of national interest and national development, the genuine patriotic zeal, dedicated, purposeful and pragmatic leadership are not left out. Other issues relating to resources, environment, education, employment, social security system, Medicare, housing, morality and ethics, law and order, are consciously attended to positively and tremendous progress are being recorded. China has adopted a scientific approach to sustainable, comprehensive and coordinated development with emphasis on regional economic integration, cultural diversity and world peace, with minimal domestic security threat, absence of daily common crimes and creating longterm social security. Official corruption has been reduced to the barest minimum.

The social conflicts and domestic economic crisis are sufficient indicators that oil-driven development is not geared towards benefiting local communities, but instead, to sustain the profitability of global markets and the acute needs of industrialized countries (Philippe, 2008; Pegg, 2006). Another feature of the oil resources in Nigeria is that it is capital intensive in its extraction process and do not generate much employment opportunities in a labor -intensive endowment like Nigeria, thus creating the paradox of plenty. Dependence on crude oil exports is the primary explanatory variable for unemployment, social conflicts, poverty, inequality, underdevelopment and macroeconomic instability. A veritable way of reversing the ugly trend is the diversification of investments (alternatively, ChinAfrica cooperation). This would help Africa and Nigeria in particular to imbibe the experiences, process, strategy and model in China's success in poverty reduction, human 
resources development, environment improvement, employment and reducing inequality (Zhuang, 2008). In the past 30 years of China's reforms and opening up, rural poverty reduction was contributed by practices (Xiaojian Fan, 2008) such as mindset emancipation, institutional innovation, self reliance, effective response to special needs of special groups and propoor empowerment. Such are needed in the Niger Delta. In the South-South cooperation, China's economic and investment policy experiences can inform Nigeria's efforts to accelerate her economic and social transformation, contribute towards the realization of the Millennium Development Goals (MDGs) and to establish a harmonious Nigeria. There are many areas in which Africa could benefit from China in this South-South Cooperation; Agricultural Technology (Biotechnology), entrepreneurial innovations, physical infrastructure, and fight against corruption in public offices, health, education, research and exchanges would yield mutual benefits and trusts. Financial, expert cum technical assistances to foster and promote indigenous scientific capacity are not left out. In this dawn of cooperation based on mutual trust and respect, Africa can begin to properly harness her rich but underused agricultural potentials. Agro-industrialization could now provide a permanent solution to the perennial conflicts of mono-structure economy. It is expected that in the next decade, the United State of America and China will emerge as the managing partners in the global economy. China in terms of economic content and Foreign Direct Investment in Nigeria are hereunder provided:

Trade volume between nigeria and china.

\begin{tabular}{|c|c|c|c|c|}
\hline Period & Total Trade Volume & $\begin{array}{l}\text { Exports to } \\
\text { Nigeria }\end{array}$ & $\begin{array}{l}\text { Imports from } \\
\text { Nigeria }\end{array}$ & Balance (in Favor of China) \\
\hline Jan-Dec 1979 & US\$32.6m & US\$24.7m & US\$7.9m & US\$16.8m \\
\hline Jan-Dec 1980 & US\$45.8m & US\$51.8m & US\$4.9m & US $\$ 49.9 \mathrm{~m}$ \\
\hline Jan-Dec 1982 & US\$26.9m & US $\$ 22.8 \mathrm{~m}$ & US\$4.1m & US $\$ 18.7 \mathrm{~m}$ \\
\hline Jan-Dec 1983 & US $\$ 10.2 \mathrm{~m}$ & US $\$ 7.0 \mathrm{~m}$ & US $\$ 3.2 \mathrm{~m}$ & US $\$ 3.8 \mathrm{~m}$ \\
\hline Jan-Dec 1988 & US $\$ 37.19 \mathrm{~m}$ & US $\$ 29.34 \mathrm{~m}$ & US $\$ 7.85 \mathrm{~m}$ & US $\$ 21.49 \mathrm{~m}$ \\
\hline Jan-Dec 1992 & US\$96.96m & US $\$ 91.0 \mathrm{~m}$ & US\$5.96m & US $\$ 85.04 \mathrm{~m}$ \\
\hline Jan-Dec 1993 & US\$121.29m & US\$120.76m & US $\$ 0.5 \mathrm{~m}$ & US $\$ 121.23 \mathrm{~m}$ \\
\hline Jan-Dec 1996 & US\$177.67m & US\$170.85m & US\$6.82m & US\$164.0m \\
\hline Jan-Dec 1997 & US\$327.0m & US\$316.4m & US $\$ 10.6 \mathrm{~m}$ & US $\$ 305.79 \mathrm{~m}$ \\
\hline Jan-Dec 1998 & US\$384.68m & US $\$ 357.2 \mathrm{~m}$ & US\$27.42m & US\$329.9m \\
\hline Jan-Dec 1999 & US\$578.43m & US\$359.9m & US\$182.49m & US $\$ 213.45 \mathrm{~m}$ \\
\hline Jan-Dec 2000 & US\$856.75m & US\$549.46m & US $\$ 307.3 \mathrm{~m}$ & US\$242.16m \\
\hline Jan-Dec 2001 & US\$1,146.8m & US\$919.35m & US\$227.44m & US\$691.92m \\
\hline Jan-Dec 2002 & US $\$ 1,195.4 \mathrm{~m}$ & US $\$ 1,074 \mathrm{~m}$ & US\$121.3m & US\$925.8m \\
\hline Jan-Dec 2003 & US $\$ 1,858.8 \mathrm{~m}$ & US $\$ 1,786.8 \mathrm{~m}$ & US\$71.68m & US $\$ 1,715.2 \mathrm{~m}$ \\
\hline Jan-Dec 2004 & US $\$ 2,182.7 \mathrm{~m}$ & US $\$ 1,719.5 \mathrm{~m}$ & US\$463.2m & US $\$ 1,256.3 \mathrm{~m}$ \\
\hline Jan-Dec 2005 & US\$1,000m & NA & NA & NA \\
\hline
\end{tabular}




\section{Trade}

Between December 2005 and December 2006, the total volume of trade has increased tremendously. Precisely, Nigeria ranks China's second largest trading partner in Africa, next to South Africa. In the area of oil, Nigeria ranks the third largest supplier of oil to China, after Sudan and Angola, while China is Nigeria's fifth largest non oil export destination. In 2007, the bilateral trade between Nigeria and China increase by 37.8, export between the two countries was up by $93.4 \%$, and import from China increased by $31.9 \%$. Over 50 major Chinese companies are engaged in various lucrative businesses in Nigeria, ranging from multimillion dollar contracts to manufacturing and tourism industries. And a large number of them engage in several forms of activities.

\section{PROBLEMS}

There are several pending economically beneficial projects between the two countries, ranging from Assisted Projects to Contracts Awarded Projects, covering Power/Energy, Railway infrastructure, health, and various social facilities, etc. The problems or the delays in the execution of some of these projects varies from administrative (bureaucratic process) to political reasons vis-à-vis the sizes, with regard to qualities and quantities and their development impacts on the overall development agenda of the country. While some are due to changes in administration that often comes with changes in policies as well as lack of pro-activeness of either Chinese contractors or government representatives and other technical reasons.

Perhaps, Chinese are yet to understand how competitive Nigeria is in Africa irrespective of whatever the so-called weaknesses some Chinese have spread about Nigeria in the Chinese website. There is the need to understand the working system in Nigeria. And the Chinese must embark on confidence building project within the official and business community particularly, with regards to upgrading the quality of their products and construction delivery, re-examine their smartness, the hit and run system or used and abandoned system that are no longer in line with the sophisticated modern public relations practice and strategic economic dialogue.

Projects must be determined according to individual countries needs and priority and not the African piecemeal presently being distributed through FOCAC. It does not mean that because African or Chinese problems appear to be similar in nature that their priorities at individual country's level or provincial level are the same. It is not how many projects we have given to Africa, but that which of the projects have been successfully executed and how much is its impact on the ordinary people. One powerfully well executed health project like general purpose hospital is enough signposts for Chinese image compare to many times parade malaria assistance that cannot be substantiated. 


\section{CONCLUSION}

The dividends derived from oil exploitation in the Niger Delta, and of globalization in general, are yet to be fairly distributed between the Niger Delta ethnic groups, the Nigerian State and the multinationals. The gains of globalization have failed to reach the African poor; they are excluded and further impoverished by the forces of globalization. Globalization has further entrenched natural resources, mineral and agricultural colonization in the continent. Marginal farmers have been deprived of their land, river and forest. The poor ethnic group could no longer control their natural resource base. The fact that western involvements in Africa have neither significantly improved the condition of the rural poor nor been effective in addressing the fundamental causes of resource degradation, points to a new direction of Africa cooperation. Nigeria in particular needs a lot of non-oil sector investments, typical of the Chinese cooperation. China's present involvement in the Nigerian energy, communication, agriculture, transport and Export Processing Zones (EPZ) is a pointer to development and pro-poor growth as China ploughs back its trade surplus in the Nigerian economy. This development approach is far better than European Union (EU) involvement in Africa, where development policies have failed, and bigger chunk of development Aids ended in the pockets of leaders, facilitators and project consultants, with no meaningful impact on the rural poor. On trade globalization, the developed countries have the capital, the technology, the military power and so on. They formulate the "rules of the game" for new world economy. They are the most active propellers and the biggest beneficiaries from globalization. From the foregoing, a globalizing world calls for South-South cooperation. All countries big or small, rich or poor, strong or weak should have a right to protect their ethnic groups and the right to equal participation in international economic decisions, especially on issues pertaining to their own development. Africa and Nigeria in particular should be allowed to choose the path of development that suits their national situation. Nigeria and China have great potentials and broad prospects for economic, political, agricultural, diplomatic, educational, technological and cultural cooperation.

\section{REFERENCES}

Ademola .O.D (2007): Culture Education and the Challenge of Globalizationin Modern Nigeria.

Akpobibibo .O (2003): Confronting the Human Security Dilema- towards Building Sustainable Peace in Niger Delta. Being a speech on the ceremony of winner (Ms Ibiba Donpredo) CNN Africa Journalists, October 18, Lambeth town, London. Ayandiji .D.A (2006): Globalization and The Retrenchment of 
African Economy- Revisiting Post $\$ 18$ billion Debt Cancellation in Nigeria. The Journal of Pan-African Studies, Vol.1, No4. Bukowski .C. and Barnabas .R, ed (1999): The Return of the Left in Post-Communist States. Elgar Publishing ltd, UK.

Bie Zhenyu, 2008, thinking on pro-poor policies in ethnic minority areas, 2008.8 Management world, 48

Collier .P and Hoeffler .A (2004): Greed and Grievances in Civil War. OxfordEconomicPapers.

Humphrey .M, Sachs J.D and Stieglitz J.E(2007): Escaping the Resource Curse. New York, Columbia University Press. Idemudia .U. and Ite U.E. (2006): Demystifying the Niger Delta Conflict- towards Integrated Exploration. Review of African Political Economy, 49(3); 14-21.

Isagani .R. and Serrano (2005): Community Development and Globalization. Being a paper presented at the international conference on Civil Society, Religion and Global Governance, 1-2 September, Canberra, Australia.

Juzhong Zhuang (2008): Inclusive Growth Toward a Harmonious Society in the People's Republic of China- Policy Implications. Asian Development Review, Vol.25, Nos 1and2. ADB. Karl .T.L (2007): Oil-Led Development- Social, Political and Economic Consequences. CDDRL working Papers, Stanford University.

Lull .J. (2000): Media Communication Culture; A Global Approach. Cambridge Polity.

Ojakorotu .V. (2008): The Internationalization of Oil Violence in The Niger Delta. Turkish Journal of International Relations, Vol.7, No.1.Being a part of Doctoral Thesis submitted to the Department of International Relations, Monish University, Johannesburg, South Africa.

Owens .W. (2001): The Paradox of Poverty and Corporate Globalization. The first EU conference on Globalization. November. Pegg .S. (2006): Can Policy Intervention Beat the Resource Curse? Evidence from the Chad-Cameroon Pipeline Project. African Affairs, 105(418);1-25.

Philippe .C. (2008): Oil for Health in Sub-Saharan Africa---Health System in Resource Curse Environment. Report in The Economist, September 11-17, 1999, p.24.

Ronnie .V. and Li Xiaoyun, Ed (2009): Community-Based Natural Resource Management; An Introduction. China Agricultural University, Beijing.

Shepard .B. and Hayduk .R.ed (2002): From Act UP to the WTO; Urban Protest and Community Building in the Era of Globalization. London, Verso.

Tade Akin-Anna, Ed (2004): Globalization and Social Policy in Africa. CODESRIA, Dakar. 
Thomson .J.B. (1995): The Media and Modernity. Cambridge Polity. Toyo -Eskor (2001): Background to Globalization. Academic Staff Union of Universities (ASUU) Publications. University of Ibadan, Nigeria.

Fan Xiaojin (2008): Poverty Alleviation and Development in China. Being a Speech at the Poverty Reduction and Development Forum. October 17, Beijing.

http://www.xjass.com/mzs/content/2008-07/25/content 25203.htm (accessed 5th Feb. 2009).

http://www.chinafupin.org/sngh/showarticle.asp( accessed 14th Jan. 2009). 